\title{
Efficacy and safety of adalimumab in Canadian patients with moderate to severe Crohn's disease: Results of the Adalimumab in Canadian SubjeCts with ModErate to Severe Crohn's DiseaSe (ACCESS) trial
}

\author{
Remo Panaccione MD¹, Edward V Loftus Jr MD², David Binion $\mathrm{MD}^{3}$, Kevin McHugh PhD ${ }^{4}$, Shamsul Alam PhD ${ }^{5}$,
} Naijun Chen $\mathrm{MS}^{5}$, Benoît Guérette $\mathrm{PhD}^{6}$, Parvez Mulani $\mathrm{PhD}^{5}$, Jingdong Chao $\mathrm{PhD}^{5}$

\begin{abstract}
R Panaccione, EV Loftus Jr, D Binion, et al. Efficacy and safety of adalimumab in Canadian patients with moderate to severe Crohn's disease: Results of the Adalimumab in Canadian SubjeCts with ModErate to Severe Crohn's DiseaSe (ACCESS) trial. Can J Gastroenterol 2011;25(8):419-425.
\end{abstract}

OBJECTIVE: To evaluate open-label adalimumab therapy for clinical effectiveness, fistula healing, patient-reported outcomes and safety in Canadian patients with moderate to severe Crohn's disease (CD) who were either naive to or previously exposed to antitumour necrosis factor (anti-TNF) therapy.

METHODS: Patients with moderate to severe CD (CD activity index [CDAI] score of greater than 220, or Harvey-Bradshaw index [HBI] of 7 or greater) were eligible. Patients received open-label adalimumab as induction (160 mg and $80 \mathrm{mg}$ subcutaneously [sc]) at weeks 0 and 2, respectively and maintenance (40 $\mathrm{mg}$ sc every other week) therapy. At or after eight weeks, patients with flare or nonresponse could have their dosage increased to $40 \mathrm{mg}$ sc weekly. Patients were followed for a minimum of six months or until adalimumab was commercially available in Canada.

RESULTS: Of the 304 patients enrolled, 160 were infliximab experienced, while 144 were anti-TNF naive. HBI remission (HBI score of 4 or lower) at week 24 was achieved by $53 \%$ of anti-TNF-naive and $36 \%$ of infliximab-experienced patients $(\mathrm{P}<0.01 ; \mathrm{P}<0.001$ for both groups for all visits versus baseline). Fistula healing rates at week 12 were $48 \%$ for anti-TNF-naive patients, and 26\% for infliximab-experienced patients. At week 24, fistula healing rates were significantly greater for the anti-TNF-naive group (60\% versus $28 \%$; $\mathrm{P}<0.01)$. Improvements in quality of life and work productivity were sustained from week 4 to week 24 for all patients. Serious infections occurred in $2 \%$ of patients. CONCLUSIONS: Adalimumab therapy induced and sustained steroidfree remission in both infliximab-experienced and anti-TNF-naive patients with moderate to severe CD. Clinically meaningful rates of fistula healing were also observed. Improvements in patient-reported outcomes were sustained throughout the 24 -week study period.

Key Words: Adalimumab; Crohn's disease; Fistula; Quality of life; Steroid-free remission; Work productivity

\author{
L'efficacité et l'innocuité de l'adalimumab chez des \\ patients canadiens ayant une maladie de Crohn \\ modérée à grave : les résultats de l'essai ACCESS sur \\ l'adalimumab chez les sujets canadiens ayant une \\ maladie de Crohn modérée à grave
} l'efficacité, la guérison des fistules, les issues déclarées par les patients et l'innocuité chez des patients canadiens atteints d'une maladie de Crohn (MC) modérée à grave qui étaient naïfs au traitement ou avaient déjà été exposés à une thérapie au facteur de nécrose antitumorale (anti-TNF).

MÉTHODOLOGIE : Les patients atteints d'une MC modérée à grave (indice d'activité de la MD [IAMC] supérieur à 220 ou indice de HarveyBradshaw [IHB] de 7 ou plus) étaient admissibles. Les patients ont reçu de l'adalimumab ouvert à l'induction $(160 \mathrm{mg}$ et $80 \mathrm{mg}$ par voie souscutanée [sc] lors des semaines 0 et 2 , respectivement) et une thérapie d'entretien (40 mg par voie sc toutes les deux semaines). Au bout de huit semaines ou par la suite, les patients présentant une récidive ou qui n'avaient pas réagi pouvaient accroître leur dose à $40 \mathrm{mg}$ par voie sc toutes les semaines. Les patients étaient suivis pendant une période minimale de six mois ou jusqu'à la mise en marché commerciale de l'adalimumab au Canada.

RÉSULTATS : Sur les 304 patients à l'étude, 160 avaient déjà pris de l'infliximab, tandis que 144 étaient naifs au traitement anti-TNF. Lors de la semaine $24,53 \%$ des patients naïfs au traitement anti-TNF et $36 \%$ des patients ayant pris de l'infliximab présentaient une rémission selon l'IHB (IHB de 4 ou moins) ( $\mathrm{P}<0,01 ; \mathrm{P}<0,001$ dans les deux groupes pour toutes les visites par rapport au début de l'étude). Lors de la semaine 12 , le taux de guérison des fistules s'élevait à $48 \%$ chez les patients naïfs au traitement anti-TNF et à $26 \%$ chez ceux ayant pris de l'infliximab. Lors de la semaine 24 , le taux de guérison des fistules était considérablement plus élevé dans le groupe naif au traitement anti-TNF (60\% par rapport à $28 \% ; \mathrm{P}<0,01)$. Les améliorations à la qualité de vie et à la productivité au travail se maintenaient entre la semaine 4 et la semaine 24 chez tous les patients. On a observé des infections graves chez $2 \%$ des patients. CONCLUSIONS : La thérapie à l'adalimumab induisait et maintenait une rémission sans prise de stéroïdes chez les patients ayant déjà pris de l'infliximab et chez ceux naïfs au traitement anti-TNF atteints d'une MC modérée à grave. On constatait également des taux de guérison des fistules significatifs sur le plan clinique. L'amélioration des issues déclarées par les patients se maintenait pendant les 24 semaines de l'étude.

13.4 cases per 100,000 person-years, and 233.7 per 100,000 population, respectively. With onset often during early adulthood $(1,2), \mathrm{CD}$ can have a lifelong impact on patients' lives and their ability to work. Complications such as abscesses, fistulas, small bowel obstructions and infections can lead to CD-related hospitalization and/or surgery, which contribute to both the direct and indirect costs of the disease.

\footnotetext{
rohn's disease (CD) is a chronic inflammatory bowel disorder in which patients with active disease often experience debilitating rates of CD in Canada are among the highest in the world. In a comprehensive study of five Canadian provinces, Bernstein et al (1) estimated that the incidence rate and prevalence (1998 to 2000) were
}

${ }^{1}$ University of Calgary, Calgary, Alberta; ${ }^{2}$ Division of Gastroenterology and Hepatology, Mayo Clinic, Rochester, Minnesota; ${ }^{3}$ University of Pittsburgh, Pittsburgh, Pennsylvania, USA; ${ }^{4}$ Abbott Laboratories, Montreal, Quebec; ${ }^{5}$ Abbott Laboratories, Abbott Park, Illinois, USA; ${ }^{6}$ Abbott Laboratories, Rungis, France

Correspondence: Dr Remo Panaccione, Division of Gastroenterology, Department of Medicine, University of Calgary, Room 6D28, Teaching, Research and Wellness Building, 3280 Hospital Drive Northwest, Calgary, Alberta T2N 1N4. Telephone 403-592-5025, fax 403-592-5050,

e-mail rpanacci@ucalgary.ca

Received for publication November 22, 2010. Accepted January 27, 2011 
Indirect costs attributed to work loss and reduced productivity constitute a significant percentage of the overall economic burden of CD $(3,4)$. Ultimately, CD can result in work disability, particularly for patients who require hospitalization or experience severe pain (5-7). Daily functioning, emotional and social well-being, and overall quality of life (QoL) are also negatively affected in patients with CD (8-10), even during periods of inactive disease (11). Patients with active CD tend to experience greater levels of distress, health anxiety and perceived stress, less social support and poorer diseasespecific QoL relative to patients with inactive disease (10).

Antitumor necrosis factor (anti-TNF) agents represent an important treatment option for managing clinical symptoms and disease activity in patients with moderate to severe CD; however, research regarding the impact of anti-TNF therapy on work productivity and QoL is limited. In CD, adalimumab, a fully human monoclonal antibody specific to TNF, is effective for inducing and maintaining remission in patients with moderate to severe disease who are naive to or experienced with anti-TNF therapy (12-15). Here, we report the results of the open-label Adalimumab in Canadian SubjeCts with ModErate to Severe Crohn's DiseaSe (ACCESS) trial, including the safety and clinical benefits of adalimumab therapy for inducing and maintaining steroid-free remission, maintaining fistula healing, and improving QoL and work productivity in Canadian patients with moderate to severe CD. The trial offers the opportunity to compare clinical outcomes for anti-TNF-naive and infliximab-experienced patients in a real-world, clinical practice setting.

\section{METHODS}

\section{Study design and patients}

ACCESS was a phase III, multicentre, open-label study of patients with moderate to severe CD conducted at 42 sites in Canada from January 27, 2007, to January 10, 2008 (www.clinicaltrials.gov, NCT00427921). Patients who were either naive to anti-TNF therapy or who failed infliximab therapy were eligible to participate in the study. Infliximab-experienced patients included primary nonresponders, those who lost response and those who developed intolerance as defined by the investigator.

Patients received open-label induction therapy of adalimumab $160 \mathrm{mg}$ and $80 \mathrm{mg}$ subcutaneously (sc) at baseline and week 2 , respectively, followed by $40 \mathrm{mg}$ sc every-other-week (eow) open-label maintenance dosing from week 4 onward. If flare or nonresponse (as determined by the investigator) occurred while the patient was receiving $40 \mathrm{mg}$ sc eow, the regimen could be changed to $40 \mathrm{mg}$ sc weekly at or after week 8. Patients were to remain in the study for a minimum of 24 weeks. Study enrollment was halted shortly after adalimumab was approved for CD in Canada on July 5, 2007. Adalimumab was provided to study participants until appropriate insurance coverage was secured. For individuals lacking insurance coverage, compassionate drug coverage was, and continues to be, provided as required.

\section{Main inclusion/exclusion criteria}

Patients 18 years of age or older with a diagnosis of CD confirmed by radiology or endoscopy for at least four months before screening with moderately to severely active CD (CD activity index [CDAI] score of greater than 220, or Harvey-Bradshaw index [HBI] score of 7 or greater) were eligible for enrollment. Patients were required to demonstrate failure to previous therapies, which included 5-aminosalicylic acid, corticosteroids and immunosuppressants (IMMs) such as azathioprine, 6-mercaptopurine and methotrexate. Infliximab-experienced patients were required to have undergone a minimum eight-week washout period (before baseline). Concomitant treatment with 5-aminosalicylates, corticosteroids and IMMs was permitted.

Exclusion criteria were as follows: persistent chronic or active nonCD-related infections that required treatment with intravenous antibiotics, antivirals or antifungals within 30 days before baseline; or oral antibiotics, antivirals or antifungals within 14 days before baseline. Patients with any of the following were also excluded: history of malignancy, other than a successfully treated nonmetastatic cutaneous squamous or basal cell carcinoma and/or localized carcinoma in situ of the cervix; history of Listeria infection, HIV or any immunodeficiency syndrome, demyelinating disease, chronic viral hepatitis or untreated tuberculosis; poorly controlled medical conditions including uncontrolled diabetes with documented history of recurrent infections, unstable ischemic heart disease, congestive heart failure, recent cerebrovascular accidents and any other condition, which in the opinion of the investigator or the sponsor, would have put the patient at risk by participating in the study; current treatment with total parenteral nutrition; any previous exposure to natalizumab; treatment with any investigational agent in the past 30 days or five half-lives before screening (whichever was longer); history of clinically significant drug or alcohol abuse in the past year; and known hypersensitivity to the excipients of adalimumab. Pregnant or breastfeeding women and women who were considering becoming pregnant during the study were not eligible.

\section{Assessments}

The primary objective was to expand the safety database of adalimumab for the treatment of Canadian patients with moderately to severely active CD. Assessment of changes in patient-reported outcomes from baseline was a secondary objective. Efficacy assessments were performed at baseline, week 4, week 12 and week 24, and at 12-week intervals thereafter until study termination. End points included clinical remission and response as measured by the HBI, QoL as measured by the Short Inflammatory Bowel Disease Questionnaire (SIBDQ), and work productivity as measured by the Work Productivity and Activity Impairment Questionnaire (WPAI). Fistula healing was also evaluated.

Clinical assessments: The HBI is a simple tool that measures CD activity by assessing general well-being, degree of abdominal pain, frequency of diarrhea, presence of abdominal mass and the presence of complications of CD. HBI remission was defined as an HBI score of 4 or lower, while HBI response was defined as a point decrease of 3 or greater in the patient's baseline HBI score. Steroid-free remission, defined as HBI remission in the absence of concomitant steroid use, was also assessed for all patients who were receiving steroids at baseline. In addition, sustained steroid-free remission was defined as being in HBI remission and steroid free for at least 90 days. The impact of baseline IMM use was assessed by evaluating HBI remission for patients with and without IMM use at baseline. HBI remission and response rates were also calculated for patients who required dosage intensification to weekly therapy, infliximab primary nonresponders and patients with elevated levels of C-reactive protein (CRP) $(10 \mathrm{mg} / \mathrm{L}$ or greater at baseline). The number of draining cutaneous abdominal and perianal fistulas (on gentle compression) was counted during each physical examination. Complete fistula healing, defined as complete closure of all fistulas that were draining at baseline, was assessed for all patients with at least one draining fistula at baseline.

Patient-reported outcomes: The SIBDQ, a simple validated, 10-item instrument, was used to assess the impact of disease on health-related QoL (HRQoL) (16). The SIBDQ gauges HRQoL in four domains: systemic, social, emotional and bowel. Questions concern patients' symptoms resulting from CD, as well as general mood and feelings, experienced during the two weeks before the visit. Total SIBDQ scores range from 10 to 70, with higher scores indicating better HRQoL.

The WPAI is a validated, self-administered, six-item instrument that assesses the impact of disease on productivity (17). As adapted for CD (18), the WPAI measures four components related to a patient's ability to work and perform regular activities of daily life: absenteeism (ie, CD-related work time missed), presenteeism (ie, CD-related work productivity loss), total work productivity impairment (TWPI) (ie, a composite of absenteeism and presenteeism) and total activity impairment (TAI) (ie, impairment of daily nonwork activities). Unemployed patients answered only select WPAI questions related to employment status and ability to perform daily activities other than work. 


\section{Safety assessments}

Safety was assessed at each visit through the evaluation of adverse events (serious and nonserious), laboratory parameters, physical examination results and vital sign measurements. In addition, adverse events were assessed (via telephone call) approximately 70 days after discontinuation of the study drug.

\section{Statistical analysis}

Effectiveness and safety data were analyzed using the intention-to-treat population, which comprised all patients who received at least one injection of adalimumab. Results were stratified according to previous exposure to infliximab (ie, anti-TNF-naive and infliximab-experienced patients).

Demographics and baseline clinical characteristics were summarized for each subgroup, and differences between anti-TNF-naive and infliximab-experienced patients were compared using Student's $t$ tests for continuous variables and $\chi^{2}$ tests for categorical variables.

Clinical remission, steroid-free remission, clinical response and fistula healing were analyzed using nonresponder imputation (NRI) analysis, in which patients with missing data for the end point in question were considered to be treatment failures. McNemar tests compared the difference in percentages of patients experiencing HBI remission and response for each visit versus baseline, and $\chi^{2}$ tests were used to compare differences between the anti-TNF-naive and infliximab-experienced groups.

Mean SIBDQ total scores for each visit versus baseline were calculated using last observation carried forward and analyzed by paired Student's $t$ tests. A nine-point change in total SIBDQ score is correlated with a 100 -point change in CDAI score (16). The impact of adalimumab on productivity was determined by comparing WPAI end points at scheduled visits versus baseline using paired Student's $t$ tests (last observation carried forward analysis). WPAI scores were calculated as a percentage of overall impairment, with $0 \%$ indicating no CD-related impairment and 100\% corresponding with total loss of work productivity/activity. The minimum clinically important difference (MCID) was defined as an absolute change of $7 \%$ or greater in the WPAI component score (19).

\section{Ethics}

The present study was conducted in accordance with the protocol, the International Conference on Harmonization guidelines, Good Clinical Practice guidelines and the Declaration of Helsinki. Independent ethics committees/institutional review boards provided approval for each of the centres participating in the trial. Each patient provided written informed consent before any study-related procedures were performed.

\section{RESULTS}

\section{Patient sample}

Demographics and clinical characteristics: Patient demographics and clinical characteristics of the 304 patients enrolled in ACCESS are summarized in Table 1. More than one-half of the population were women, baseline HBI scores were consistent with moderate to severe CD $($ mean $=12)$, and approximately one-half of all patients were receiving steroids and/or IMMs at baseline. Approximately 50\% of patients were infliximab experienced $(n=160)$.

The infliximab-experienced and anti-TNF-naive subgroups were similar in terms of CD severity and baseline CRP concentration (Table 1). Infliximab-experienced patients experienced a significantly greater median duration of CD (12.2 versus 7.4 years) and less aminosalicylate use (12\% versus $32 \%)$ compared with anti-TNF-naive patients (both $\mathrm{P}<0.0001$ ). At least one draining fistula was present in $27 \%$ of infliximab-experienced patients versus $17 \%$ of anti-TNFnaive patients $(\mathrm{P}=0.05)$. Baseline TWPI and TAI scores indicated substantial CD-related impairment for both subgroups. Likewise, baseline SIBDQ scores indicated that the study population experienced a relatively poor QoL.
TABLE 1

Baseline demographics and clinical characteristics

\begin{tabular}{|c|c|c|c|c|}
\hline & $\begin{array}{l}\text { Infliximab } \\
\text { experienced } \\
(n=160)\end{array}$ & $\begin{array}{c}\text { Anti-TNF } \\
\text { naive }(n=144)\end{array}$ & $\begin{array}{c}\text { All } \\
\text { adalimumab } \\
(n=304)\end{array}$ & $\mathrm{P}^{*}$ \\
\hline Female, \% & 55.0 & 59.0 & 56.9 & 0.48 \\
\hline $\begin{array}{l}\text { Age, years, } \\
\text { mean } \pm \text { SD }\end{array}$ & $37 \pm 12$ & $37 \pm 12$ & $37 \pm 12$ & 0.90 \\
\hline $\mathrm{HBI}$, mean $\pm \mathrm{SD}$ & $13 \pm 6$ & $12 \pm 4$ & $12 \pm 5$ & 0.11 \\
\hline $\begin{array}{l}\text { At least } 1 \text { draining } \\
\text { fistula }^{\dagger}, \%\end{array}$ & 26.9 & 17.5 & 22.4 & 0.05 \\
\hline Steroid use, \% & 44.4 & 50.7 & 47.4 & 0.27 \\
\hline $\begin{array}{l}\text { Immunosuppressant } \\
\text { use, } \%\end{array}$ & 50.0 & 42.4 & 46.4 & 0.18 \\
\hline $\begin{array}{l}\text { Aminosalicylate } \\
\text { use, } \%\end{array}$ & 11.9 & 31.9 & 21.4 & $<0.0001$ \\
\hline $\begin{array}{l}\text { Disease duration, } \\
\text { years, median }\end{array}$ & 12.2 & 7.4 & 9.5 & $<0.0001$ \\
\hline $\begin{array}{l}\mathrm{CRP}, \mathrm{mg} / \mathrm{L} \\
\text { mean } \pm \mathrm{SD}\end{array}$ & $20 \pm 30$ & $20 \pm 20$ & $20 \pm 30$ & 1.0 \\
\hline SIBDQ, mean \pm SD & $36 \pm 10$ & $35 \pm 10$ & $36 \pm 10$ & 0.66 \\
\hline $\begin{array}{l}\text { Employed at } \\
\text { baseline, \% }\end{array}$ & 60.6 & 68.1 & 64.1 & 0.18 \\
\hline \multicolumn{5}{|c|}{ WPAI component scores ${ }^{\ddagger}$, mean \pm SD } \\
\hline Absenteeism & $14 \pm 23$ & $18 \pm 32$ & $16 \pm 28$ & 0.27 \\
\hline Presenteeism & $53 \pm 26$ & $48 \pm 25$ & $50 \pm 25$ & 0.20 \\
\hline TWPI & $57 \pm 27$ & $57 \pm 27$ & $57 \pm 27$ & 0.98 \\
\hline TAI & $65 \pm 23$ & $61 \pm 25$ & $63 \pm 24$ & 0.20 \\
\hline
\end{tabular}

${ }^{*} P$ values comparing infliximab-experienced versus antitumour necrosis factor (anti-TNF)-naive groups ( $\mathrm{t}$ tests were used for continuous variables except disease duration, while $\chi^{2}$ tests were used for categorical variables. Disease duration was not normally distributed and, therefore, Wilcoxon's signed-rank test was used); ${ }^{\dagger}$ The denominators for patients with at least one draining fistula at baseline were based on nonmissing data (one patient in the anti-TNFnaive group had missing baseline fistula count data); ${ }^{\ddagger}$ Mean absenteeism, presenteeism and total work productivity impairment (TWPI) scores were determined for employed patients at baseline, whereas mean total activity impairment (TAl) scores were calculated using data from both employed and unemployed patients. CRP C-reactive protein; HBI Harvey-Bradshaw index; SIBDQ Short Inflammatory Bowel Disease Questionnaire; WPAI Work Productivity and Activity Impairment Questionnaire

Patient disposition

Nineteen per cent (31 of 160 patients) of infliximab-experienced patients discontinued the study compared with $13 \%$ (19 of 144 patients) of anti-TNF-naive patients (Figure 1). For both groups, adverse events were the most common reason for withdrawing from the study (14 patients [10\%] anti-TNF naive, 19 patients [12\%] infliximab experienced). CD and bowel obstruction were the most common adverse events in patients who withdrew from the study.

\section{Effectiveness}

HBI remission and response: Adalimumab therapy significantly improved HBI scores, with a mean change from baseline to week 24 of $-6.4 \pm 5.03(95 \%$ CI -6.96 to -5.75$)$ for all patients. For all adalimumab-treated patients, the HBI remission rate increased from $27 \%$ at week 4 to $44 \%$ at week 24 (Figure 2A). For both anti-TNFnaive and infliximab-experienced subgroups, clinical remission rates at each visit from weeks 4 to 24 of adalimumab therapy were significantly higher compared with baseline. Starting at week 8, remission rates were significantly higher for anti-TNF-naive patients than for infliximab-experienced patients. At week 24, 53\% of anti-TNF-naive and $36 \%$ of infliximab-experienced patients achieved clinical remission $(\mathrm{P}<0.01)$. For HBI response among all adalimumab-treated patients, 


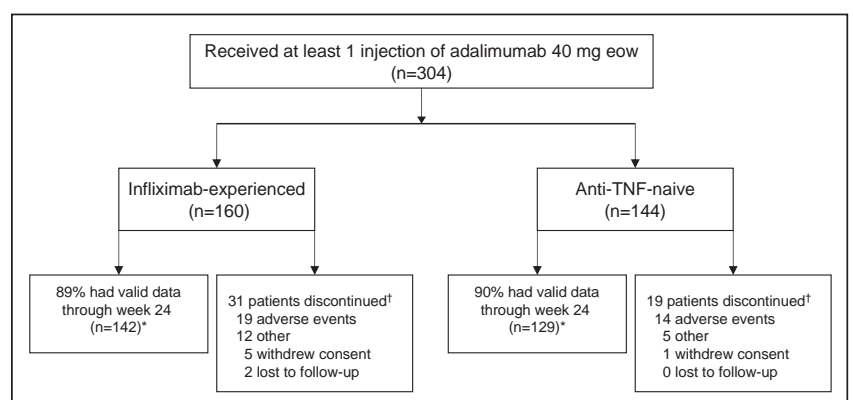

Figure 1) Patient disposition. *Some patients discontinued before week 24 but were considered to have valid week 24 data because a prespecified visit window was applied (week-24 visit window = day 128 to 211); therefore, the sum of the number of patients with valid data at week 24 and the number of patients who discontinued is greater than the $n=160$ and $n=144$ for the infliximab-experienced and antitumour necrosis factor (anti-TNF)-naive groups, respectively. 'Patients could have had more than one reason for discontinuation, but were counted only once in the total; therefore, the sum of the individual reasons for discontinuation is greater than the total number of patients who discontinued. eow Every other week
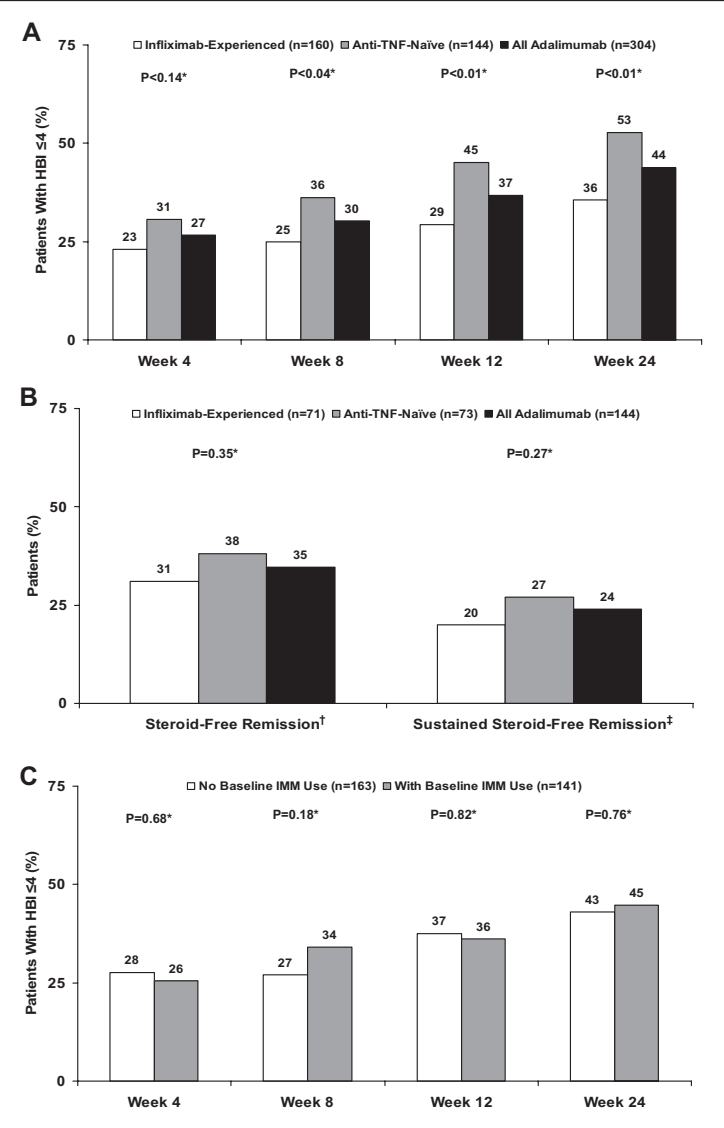

Figure 2) Nonresponder imputation analysis of clinical remission and response with adalimumab therapy. A Clinical remission (Harvey-Bradshaw index [HBI] score of 4 or lower). *P values for antitumour necrosis factor (antiTNF)-naive versus infliximab-experienced patients calculated using $\chi^{2}$ tests. $P<0.001$ for all visits versus baseline for both anti-TNF-naive and infliximabexperienced groups (McNemar's test). B Steroid-free and sustained steroid-free remission with adalimumab therapy at week 24 . All patients who were receiving steroids at baseline were included in the analysis. *P values for anti-TNFnaive versus infliximab-experienced patients calculated using $\chi^{2}$ tests; ${ }^{\dagger} \mathrm{HBI}$ score of 4 or lower, and steroid free; ${ }^{\$}$ Steroid free for at least 90 days and in HBI remission (HBI score of 4 or lower). C Clinical remission (HBI score of 4 or lower) according to baseline immunosuppressant (IMM) use. ${ }^{*} P$ values for baseline IMM use versus no baseline IMM use calculated using $\chi^{2}$ tests
$64 \%$ and $73 \%$ of patients, respectively, achieved a baseline decrease of three points or greater at weeks 4 and 24, respectively. According to subgroup, $69 \%$ of anti-TNF-naive and 59\% of infliximab-experienced patients $(\mathrm{P}>0.05)$ were responders at week 4 . From week $8(68 \%$ and $57 \%$, respectively; $\mathrm{P}<0.05)$ to week $24(82 \%$ and $65 \%$, respectively; $\mathrm{P}<0.001$ ), significantly more anti-TNF-naive patients achieved $\mathrm{HBI}$ clinical response compared with infliximab-experienced patients.

The infliximab-experienced group included 22 primary nonresponders. Remission rates in this subgroup were $5 \%$ at week 4 and $18 \%$ at week 24; response rates were $32 \%$ at week 4 and $68 \%$ at week 24 . During the trial, 120 (39\%) patients had their dosage increased to weekly adalimumab therapy. For patients who switched to weekly therapy, which was allowed at or after week 8 at the investigator's discretion but was not based on any predefined objective response criteria, $15 \%$ were in remission at week 4 and $30 \%$ were in remission at week 24; corresponding response rates were $58 \%$ and $71 \%$, respectively. Remission and response rates for patients with elevated CRP levels $(n=155)$ were $29 \%$ and $68 \%$, respectively, at week 4 and $47 \%$ and $74 \%$, respectively, at week 24 .

Among all patients receiving steroids at baseline, 35\% achieved steroid-free remission and $24 \%$ achieved sustained steroid-free remission (ie, off steroids for at least 90 days and in remission) at week 24. Adalimumab was effective for inducing steroid-free remission in both infliximab-experienced and anti-TNF-naive patients. At week 24, $31 \%$ of infliximab-experienced and $38 \%$ of anti-TNF-naive patients who were taking steroids at baseline were in steroid-free remission $(\mathrm{P}=0.35)$ (Figure 2B [NRI analysis]). In addition, 20\% of infliximabexperienced and $27 \%$ of anti-TNF-naive patients achieved sustained steroid-free remission $(\mathrm{P}=0.27)$. With respect to baseline IMM use, clinical remission rates at each time point were similar for patients who were receiving IMMs compared with those not receiving IMMs (Figure 2C).

Fistula healing: Of the $22 \%$ of patients with at least one draining fistula at baseline, 34\% (23 of 68 patients) had no draining fistulas at week 12 and 40\% (27 of 68) had no draining fistulas at week 24. Fistula healing rates increased from $48 \%$ at week 12 to $60 \%$ at week 24 for antiTNF-naive patients $(n=25)$ and from $26 \%$ at week 12 to $28 \%$ at week 24 for infliximab-experienced patients $(n=43)$ (Figure 3$)$. Significantly more patients in the anti-TNF-naive group experienced complete fistula healing at week 24 compared with patients in the infliximabexperienced group $(\mathrm{P}<0.01)$.

\section{Patient-reported outcomes}

SIBDQ: Clinically significant improvements in SIBDQ scores were observed after four weeks of adalimumab treatment (mean visit values of 36 at baseline and 46 at week 4) for the overall population (Figure 4). This improvement in HRQoL was sustained through week 24 (mean visit value of 50). Compared with baseline, both anti-TNF-naive and infliximab-experienced patients experienced improvements in mean SIBDQ scores of 9 points or greater from weeks 4 to 24 , which corresponds to a 100 point change in CDAI (Figure 4) (16).

WPAI: Adalimumab therapy was associated with substantial improvements in work productivity and ability to perform daily nonwork activities. For the population overall, TWPI mean scores improved from 56 at baseline to 29 at week 24, and TAI mean scores improved from 63 at baseline to 33 at week 24 (Figures 5A and 5B). Starting at week 4 of adalimumab therapy, both infliximab-experienced and antiTNF-naive patients achieved clinically and statistically significant TWPI and TAI improvements from baseline. For patients who were employed at baseline, clinically important TWPI changes of at least three times the MCID were observed at week 4 and were maintained through week 24 (Figure 5A $[\mathrm{P}<0.05$ for all comparisons versus baseline]). For the absenteeism component, statistically significant improvements from baseline were observed at week 12 for the anti-TNF-naive group ( -8.8 points) and at week 4 ( -7.2 points), week 8 (-9.2 points) and week 24 ( -7.6 points) for the infliximab-experienced group. A two- to threefold improvement in presenteeism scores, relative to the 


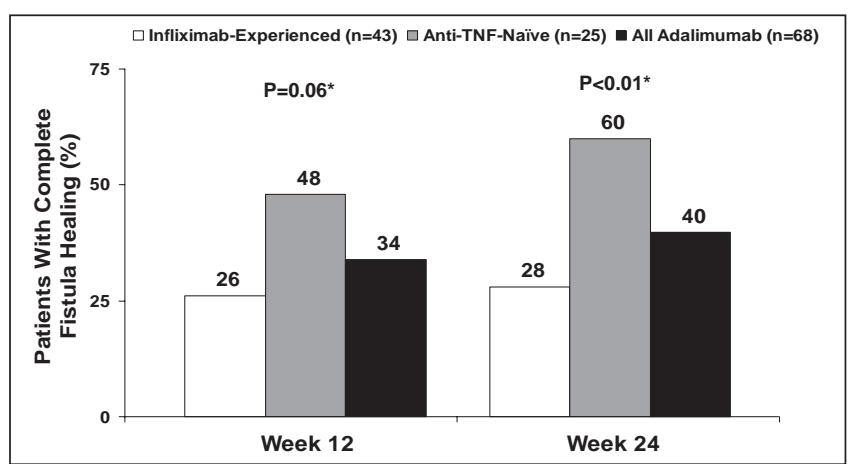

Figure 3) Nonresponder imputation analysis of sustained closure of baseline fistulas. All patients with at least one draining fistula at baseline were included in the analysis. Fistula closure was defined as complete healing of all fistulas that were draining at baseline. ${ }^{*} P$ values for antitumour necrosis factor (TNF)-naive versus infliximab-experienced patients were calculated using $\chi^{2}$ tests

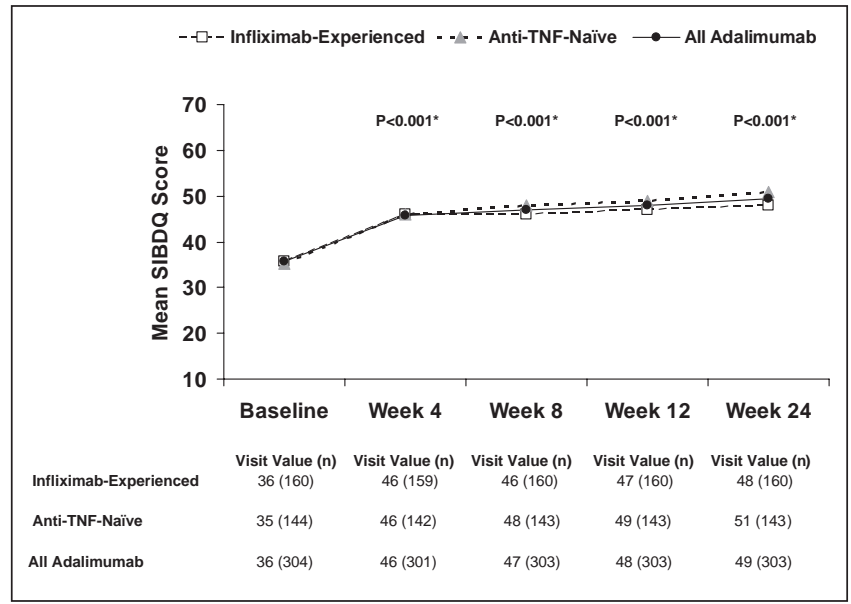

Figure 4) Last observation carried forward analysis of improvements in health-related quality of life from baseline to week 24 (within group comparisons). ${ }^{*} P<0.001$ for all visits versus baseline (Short Inflammatory Bowel Disease Questionnaire [SIBDQ] visit values minus SIBDQ baseline values; paired Student's t test) for both antitumour necrosis factor (anti-TNF)naive and infliximab-experienced groups

MCID, was observed at each time point for both the anti-TNF-naive and infliximab-experienced subgroups (all $\mathrm{P}<0.0001$ ); the greatest changes in presenteeism were observed at week $24(-25.5$ points and -25.7 points compared with baseline, respectively). At the final visit, $69 \%$ of patients (74\% anti-TNF naive and $64 \%$ of infliximab experienced) were employed compared with $64 \%$ at baseline (68\% antiTNF naive, $60 \%$ infliximab experienced). TAI scores improved by 3 to 4 times the MCID throughout the study, indicating less impairment in daily nonwork activities for both anti-TNF-naive and infliximab-experienced patients (employed and unemployed patients combined) (Figure 5B [ $\mathrm{P}<0.05$ for all comparisons versus baseline $]$ ).

\section{Safety}

Adverse events: Overall, $80 \%$ of patients experienced at least one adverse event during the study (Table 2). Anti-TNF-naive patients experienced more obstructions of the small intestine compared with infliximab-experienced patients (eight patients [5.6\%] and one patient [0.7\%], respectively), which contributed to the greater rate of serious adverse events in the anti-TNF-naive group (17.4\% versus $11.9 \%$, respectively). Eight patients experienced serious infections: two in the infliximab-experienced group and six in the anti-TNF-naive group. For all except one patient with Legionella pneumonia and one patient

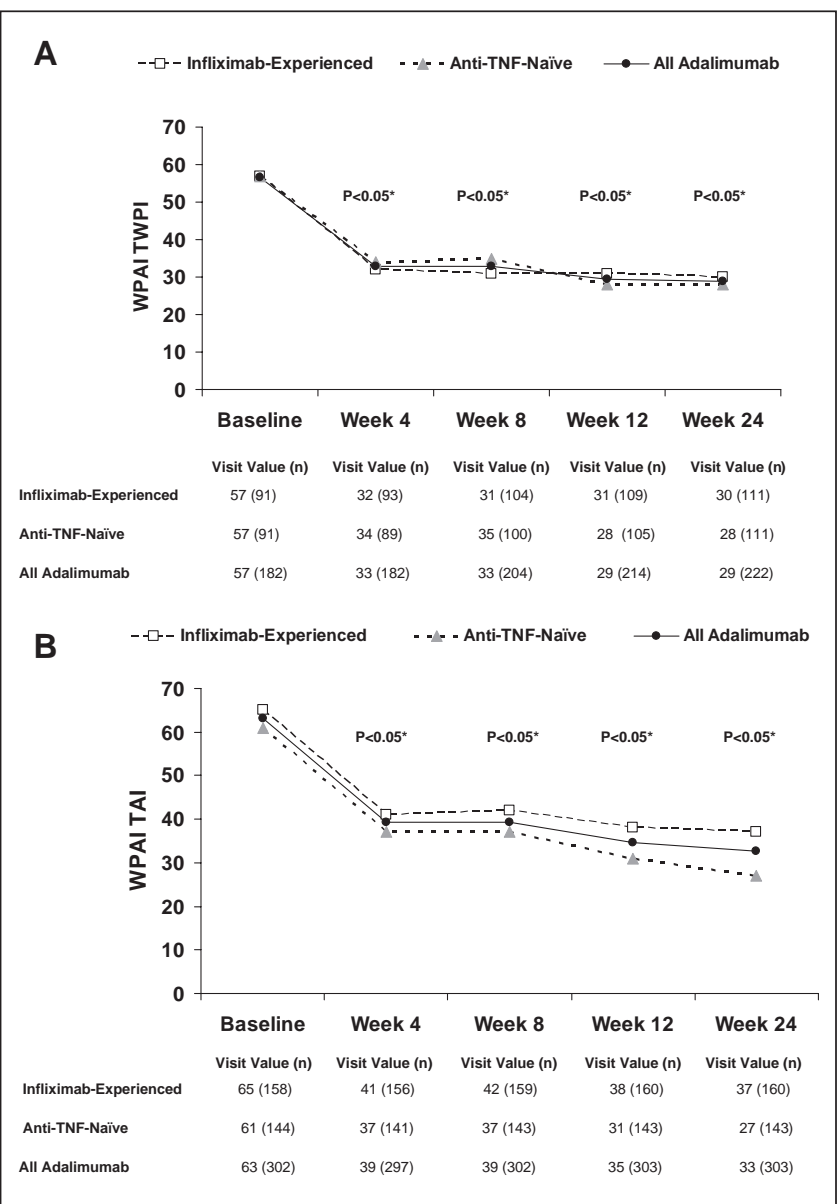

Figure 5) Last observation carried forward analysis of work productivity and activity impairment (WPAI) questionnaire component scores from baseline to week 24 (within-group comparisons). A Total work productivity impairment (TWPI) index: employed patients. B Total activity impairment (TAI) index: all patients. $* P<0.05$ compared with baseline value for both antitumour necrosis factor (anti-TNF)-naive and infliximab-experienced groups. An absolute change of $7 \%$ or more is considered to be the minimum clinically important difference

with acute appendicitis in the anti-TNF-naive group, all serious infections involved abscesses. Four patients developed opportunistic infections, all of which were nonserious oral candidiasis. One infliximab-experienced patient, a 33-year-old man with a history of smoking, azathioprine use, stricture with small bowel resection and ileal resection with right hemicolectomy, died on day 56 (abdominal pain). The death occurred 13 days after the final treatment and was considered as probably not related to adalimumab. Additional details of this death were not available; however, a family member reported that the patient had been feeling quite well approximately four days before his death, but began to experience abdominal discomfort two days before death. No cases of lymphoma, nonmelanoma skin cancer, congestive heart failure, demyelinating disorder, lupus-like syndrome or tuberculosis were reported.

\section{DISCUSSION}

The goals of therapy when treating a patient with CD should include the rapid induction of remission, steroid sparing and improvement in QoL. In addition, increased work productivity is important both to individuals and to society. Patients with fistulas experience a significant impact on QoL; therefore, fistula healing is paramount. QoL improvements should include increasing work productivity, ability to perform daily activities and emotional well-being. Previous controlled trials have shown adalimumab to be effective for inducing sustained 


\begin{tabular}{|c|c|c|c|c|c|c|}
\hline & \multicolumn{2}{|c|}{$\begin{array}{c}\text { Infliximab experienced }(n=160) \\
(P Y s=69.7)\end{array}$} & \multicolumn{2}{|c|}{$\begin{array}{c}\text { Anti-TNF naive }(\mathrm{n}=144) \\
\text { (PYs=62.8) }\end{array}$} & \multicolumn{2}{|c|}{$\begin{array}{c}\text { All adalimumab }(n=304) \\
(P Y s=132.5)\end{array}$} \\
\hline Any adverse event & $125(78.1)$ & $511(733.1)$ & $117(81.3)$ & $460(732.5)$ & $242(79.6)$ & $971(732.8)$ \\
\hline Serious adverse event & $19(11.9)$ & $30(43.0)$ & $25(17.4)$ & $4(63.7)$ & $44(14.4)$ & $70(52.8)$ \\
\hline Leading to discontinuation of study drug & $19(11.9)$ & $26(37.3)$ & $14(9.7)$ & $14(22.3)$ & $33(10.9)$ & $40(30.2)$ \\
\hline Fatal adverse event* & $1(0.6)$ & $2(2.9)$ & 0 & 0 & $1(0.3)$ & $2(1.5)$ \\
\hline Infection & $45(28.1)$ & $73(104.7)$ & $45(31.3)$ & $63(100.3)$ & $90(29.6)$ & $136(102.6)$ \\
\hline Serious infection & $2(1.3)^{\dagger}$ & $3(4.3)$ & $6(4.2)^{\ddagger}$ & $6(9.6)$ & $8(2.6)$ & $9(6.8)$ \\
\hline Injection-site reaction & $35(21.9)$ & $53(76.0)$ & $22(15.3)$ & $36(57.3)$ & $57(18.8)$ & $89(67.2)$ \\
\hline Hepatic disorder & $2(1.3)$ & $2(2.9)$ & $3(2.1)$ & $4(6.4)$ & $5(1.6)$ & $6(4.5)$ \\
\hline Opportunistic infection§ & $1(0.6)$ & $1(1.4)$ & $3(2.1)$ & $3(4.8)$ & $4(1.3)$ & $4(3.0)$ \\
\hline Tuberculosis & 0 & 0 & 0 & 0 & 0 & 0 \\
\hline Congestive heart failure & 0 & 0 & 0 & 0 & 0 & 0 \\
\hline Demyelinating disorder & 0 & 0 & 0 & 0 & 0 & 0 \\
\hline Lupus-like syndrome & 0 & 0 & 0 & 0 & 0 & 0 \\
\hline
\end{tabular}

${ }^{*}$ One death (abdominal pain) was reported during the study. The patient died on day 56 (13 days after the final dose of adalimumab); ${ }^{\dagger}$ Abdominal abscess ( $\left.n=1\right)$ and intra-abdominal pelvic abscess $(n=1)$ in the infliximab-experienced group; ${ }^{\ddagger}$ Intra-abdominal abscess $(n=2)$, Legionella pneumonia ( $\left.n=1\right)$, perianal abscess ( $\left.n=1\right)$, right-sided ischiorectal abscess ( $n=1)$ and acute appendicitis $(n=1)$ in the antitumour necrosis factor (TNF)-naive group; ${ }^{\S}$ All opportunistic infections were oral candidiasis; "Metastatic lung adenocarcinoma. E Events; PYs Patient years

remission and steroid-free remission (13), maintaining complete fistula closure (20) and improving HRQoL (21) in patients with moderately to severely active CD.

Results from the present open-label study, which was designed to reflect a real-world clinical practice setting in Canadian patients eligible to receive anti-TNF therapy for CD, are supportive of previous findings in both anti-TNF-naive and infliximab-experienced patients. Rates of clinical remission, steroid-free remission and fistula healing in ACCESS were similar to those observed at week 26 in the placebocontrolled, 56-week Crohn's Trial of the Fully Human Antibody Adalimumab for Remission Maintenance (CHARM) (13), in which $40 \%$ (32\% anti-TNF experienced and $47 \%$ anti-TNF naive) of randomized responders treated with adalimumab $40 \mathrm{mg}$ eow were in remission. However, it is important to note that clinical remission in CHARM was defined as a CDAI score of less than 150, whereas in ACCESS, remission was defined as an HBI of 4 or lower. The week-26 fistula healing rate for the combined biotherapy-naive and infliximabexperienced population in CHARM was $30 \%$, and $19 \%$ of patients receiving adalimumab eow therapy achieved sustained steroid-free remission at week 26 (13). When stratified according to baseline IMM use, week-26 remission rates in CHARM were 39\% for patients with IMM use and $42 \%$ for those without IMM use (13).

Results from ACCESS were also consistent with those observed in Crohn's Treatment with Adalimumab: Patient Response to a Safety and Efficacy Study, a study with a similar design conducted in Europe (22). In CARE, HBI remission rates at week 20 of open-label adalimumab therapy were $61 \%$ for anti-TNF-naive patients and $42 \%$ for infliximab-experienced patients; fistula healing rates were $33 \%$ and $22 \%$, respectively; and remission rates at week 20 were similar regardless of baseline IMM use (55\% with IMM use versus 49\% without IMM use). Although clinical outcomes for anti-TNF-naive patients tended to be better than those for infliximab-experienced patients, patients who failed infliximab therapy achieved clinically significant improvements with subsequent adalimumab therapy $36 \%$ in $\mathrm{HBI}$ remission and 19\% with complete fistula healing at week 20 [NRI analysis]). Approximately one-half of patients in ACCESS had failed treatment with infliximab; thus, this study supports the effectiveness of adalimumab in this difficult-to-treat population.

Patients in ACCESS had substantial HRQoL and productivity impairments at baseline, and adalimumab maintenance therapy was equally effective for improving patient-reported outcomes, as measured by the SIBDQ and WPAI, in both biologic-naive and infliximabexperienced patients. These results are consistent with those from other trials that investigated the impact of biologic therapy on HRQoL in patients with $\mathrm{CD}(21,23,24)$.

Recent estimates of the economic burden of CD in terms of direct medical costs and indirect costs to society (eg, work loss and workforce nonparticipation) in Canada are available in a report from the Crohn's and Colitis Foundation of Canada (25). Total indirect costs of inflammatory bowel disease (IBD) are estimated to account for more than $\$ 1$ billion of the estimated $\$ 1.8$ billion total IBD-related costs, with the indirect costs of CD specifically accounting for $\$ 595$ million (2008 \$CAD) (25). Long-term work loss, out-of-pocket expenses and short-term work loss (eg, absenteeism) comprised the majority of these indirect costs. For patients with IBD, labour force nonparticipation was estimated to be $3 \%$ to $13 \%$ greater than that for the general public, and the burden of long-term work loss costs exceeded $\$ 746$ million per year (2008 \$CAD). Indirect medical costs of shortterm work loss in Canadian patients with IBD were estimated to be approximately $\$ 138$ million per year (2008 \$CAD). These costs reflect that an estimated $43 \%$ of patients with IBD require diseaserelated time off from work ( 7.2 days per employed person with IBD per year).

Our analysis of work productivity, which used the recently validated CD-specific version of the WPAI (18), indicates that adalimumab can provide sustained improvement in overall work productivity for patients with moderately to severely active CD. Productivity outside of work was also substantially improved. A recent analysis from the Manitoba IBD Cohort Study reported that although employment rates for patients with IBD were similar to those for the community controls, patients with IBD reduced their daily and work activities and missed more work days (26). Furthermore, IBD-related sick leave has 
been shown to have a greater negative impact on $\mathrm{HRQOL}$ than that of unemployment and work disability (27). These findings are important in the context of the potential for work and overall productivity improvements to offset a portion of any increases in direct medical costs for biologic therapies as well as to reduce work loss and workforce nonparticipation costs incurred by employers and patients.

Limitations of the present study include the relatively short 24-week duration, the open-label and uncontrolled design, and the fact that strict inclusion/exclusion criteria were not used. In addition, infliximab failure was determined by the investigator rather than by prespecified clinical criteria. Although the current study enrolled patients who were primary nonresponders to infliximab, the small sample size (approximately 15\% of the study population) limited the ability to draw meaningful conclusions in this population.

\section{SUMMARY}

Adalimumab therapy induced and sustained steroid-free remission and led to clinically meaningful rates of fistula healing for both anti-TNF-naive and infliximab-experienced patients with moderate to severe CD. In addition, adalimumab therapy significantly improved HRQoL, increased work productivity and decreased daily nonwork activity impairment. Improvements in all measures of disease activity and patient-reported outcomes were maintained throughout the 24-week study period. The overall safety profile in ACCESS was consistent with a recently published, comprehensive safety analysis of six adalimumab trials in patients with moderate to severe CD (28).

FINANCIAL DISCLOSURES: Dr Panaccione has served as consultant for Biogen Idec, Abbott, Ferring, Merck, Schering-Plough, Shire, Centocor Ortho Biotech, Elan, GlaxoSmithKline, UCB, Proctor and Gamble, and Bristol Myers Squibb; has served on the speaker's bureau for Abbott, Axcan, Centocor Ortho Biotech, Elan, Schering-Plough, Shire, Prometheus, and Proctor and Gamble; has served on the advisory board for Abbott, Ferring, Schering-Plough, Shire, Elan, and Proctor and Gamble; and has received research/educational support from Abbott, Ferring, Axcan, Jansen, Schering-Plough, Centocor, Millenium, Elan, Proctor and Gamble, and Bristol Myers Squibb. Dr Loftus has consulted for Abbott, Centocor Ortho Biotech, Procter \& Gamble and UCB, and received research support from Abbott, ActoGeniX, Otsuka America, and UCB. Dr Binion has received grant support from Biogen, Centocor, Elan, National Institutes of Health, and Procter \& Gamble; and served on advisory boards for Abbott and UCB. Drs McHugh, Guérette, Mulani, and Chao, and $\mathrm{Mr}$ Chen are employees of Abbott Laboratories. Dr Alam was an employee of Abbott Laboratories when this research was conducted. Drs Mulani and Chao own Abbott stock.

ACKNOWLEDGEMENT: The ACCESS study and all data analyses were funded by Abbott Laboratories, Abbott Park, Illinois, USA. The authors thank Jimmy Baloukas from clinical operations at the Canadian Affiliate for project management. Cathryn M Carter MS, of Arbor Communications Inc, provided medical writing services in the development and revision of the manuscript; this support was funded by Abbott.

\section{REFERENCES}

1. Bernstein CN, Wajda A, Svenson LW, et al. The epidemiology of inflammatory bowel disease in Canada: A population-based study. Am J Gastroenterol 2006;101:1559-68.

2. Loftus E. Clinical epidemiology of inflammatory bowel disease: Incidence, prevalence and environmental influences. Gastroenterology 2004;126:1504-17.

3. Feagan BG, Bala M, Yan S, Olson A, Hanauer S. Unemployment and disability in patients with moderately to severely active Crohn's disease. J Clin Gastroenterol 2005;39:390-5.

4. Stark R, König HH, Leidl R. Costs of inflammatory bowel disease in Germany. Pharmacoeconomics 2006;24:797-814.

5. Ananthakrishnan AN, Weber LR, Knox JF, et al. Permanent work disability in Crohn's disease. Am J Gastroenterol 2008;103:154-61.

6. Longobardi T, Jacobs P, Bernstein CN. Work losses related to inflammatory bowel disease in the United States: Results from the
National Health Interview Survey. Am J Gastroenterol 2003;98:1064-72.

7. Longobardi T, Jacobs P, Bernstein CN. Work losses related to inflammatory bowel disease in Canada: Results from a national population health survey. Am J Gastroenterol 2003;98:844-9.

8. Blondel-Kucharski F, Chircop C, Marquis P, et al. Health-related quality of life in Crohn's disease: A prospective longitudinal study in 231 patients. Am J Gastroenterol 2001;96:2915-20.

9. Cohen RD. The quality of life in patients with Crohn's disease. Ailment Pharmacol Ther 2002;9:1603-9.

10. Graff LA, Walker JR, Lix L, et al. The relationship of inflammatory bowel disease type and activity to psychological functioning and quality of life. Clin Gastroenterol Hepatol 2006;4:1491-501.

11. Lix LM, Graff LA, Walker JR, et al. Longitudinal study of quality of life and psychological functioning for active, fluctuating, and inactive disease patterns in inflammatory bowel disease. Inflamm Bowel Dis 2008;14:1575-84.

12. Hanauer SB, Sandborn WJ, Rutgeerts P, et al. Human anti-tumor necrosis factor monoclonal antibody (adalimumab) in Crohn's disease: The CLASSIC I trial. Gastroenterology 2006;130:323-33.

13. Colombel J-F, Sandborn WJ, Rutgeerts P, et al. Adalimumab for maintenance of clinical response and remission in patients with Crohn's disease: The CHARM trial. Gastroenterology 2007;132:52-65.

14. Sandborn WJ, Hanauer SB, Rutgeerts PJ, et al. Adalimumab for maintenance treatment of Crohn's disease: Results of the CLASSIC II trial. Gut 2007;56:1232-9.

15. Sandborn WJ, Rutgeerts P, Enns R, et al. Adalimumab induction therapy for Crohn's disease previously treated with infliximab. Ann Intern Med 2007;146:829-38.

16. Irvine EJ, Zhou Q, Thompson AK. The Short Inflammatory Bowel Disease Questionnaire: A quality of life instrument for community physicians managing inflammatory bowel disease. CCRPT Investigators. Canadian Crohn's Relapse Prevention Trial. Am J Gastroenterol 1996;91:1571-8.

17. Reilly MC, Zbrozek AS, Dukes EM. The validity and reproducibility of a work productivity and activity impairment instrument. Pharmacoeconomics 1993;4:353-65.

18. Reilly MC, Gerlier L, Brabant Y, Brown M. Validity, reliability, and responsiveness of the Work Productivity and Activity Impairment questionnaire in Crohn's disease. Clin Ther 2008;30:393-404.

19. Reilly MC, Brown MC, Brahant Y, Gerlier L, Tan SC, Sandborn WJ. Defining the minimally important difference for WPAI: CD Scores: What is a relevant impact on work productivity in active Crohn's disease? Gut 2007;56(Suppl 3):A159. (Abst)

20. Colombel JF, Schwartz DA, Sandborn, et al. Adalimumab for the treatment of fistulas in patients with Crohn's disease. Gut 2009;58:940-8.

21. Loftus EV, Feagan BG, Colombel J-F, et al. Effects of adalimumab maintenance therapy on health-related quality of life of patients with Crohn's disease: Patient-reported outcomes of the CHARM trial. Am J Gastroenterol 2008;103:3132-41. (Erratum in 2009;104:1894].

22. Lofberg R, Louis E, Reinisch W, et al. Adalimumab produces clinical remission and reduces extraintestinal manifestations in Crohn's disease: Results from CARE 2011. Inflamm Bowel Dis 2011 [Epub ahead of print] doi: 10.1002/ibd.21663.

23. Feagan BG, Coteur G, Tan S. Keininger DL, Schreiber S. Clinically meaningful improvement in health-related quality of life in a randomized controlled trial of certolizumab pegol maintenance therapy for Crohn's disease. Am J Gastroenterol 2009;104:1976-83.

24. Lichtenstein GR, Yan S, Bala M, Hanauer S. Remission in patients with Crohn's disease is associated with improvement in employment and quality of life and a decrease in hospitalizations and surgeries. Am J Gastroenterol 2004;99:91-6.

25. Crohn's and Colitis Foundation of Canada. The Burden of Inflammatory Bowel Disease (IBD) in Canada. 2008. < http://www. ccfc.ca/English/images/proclamations/BIBDC\%20FINAL\%20 October\%2029th\%20EN.pdf > (Accessed on May 5, 2010).

26. Rogala L, Miller N, Graff LA, et al. Population-based controlled study of social support, self-perceived stress, activity and work issues, and access to health care in inflammatory bowel disease. Inflamm Bowel Dis 2008;14:526-35.

27. Bernklev T, Jahnsen J, Henriksen M, et al. Relationship between sick leave, unemployment, disability, and health-related quality of life in patients with inflammatory bowel disease. Inflamm Bowel Dis 2006;12:402-12.

28. Colombel J-F, Sandborn WJ, Panaccione R, et al. Adalimumab safety in global clinical trials of patients with Crohn's disease. Inflamm Bowel Dis 2009;15:1308-19. 


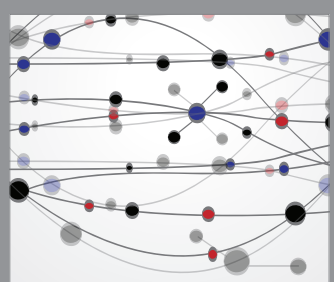

The Scientific World Journal
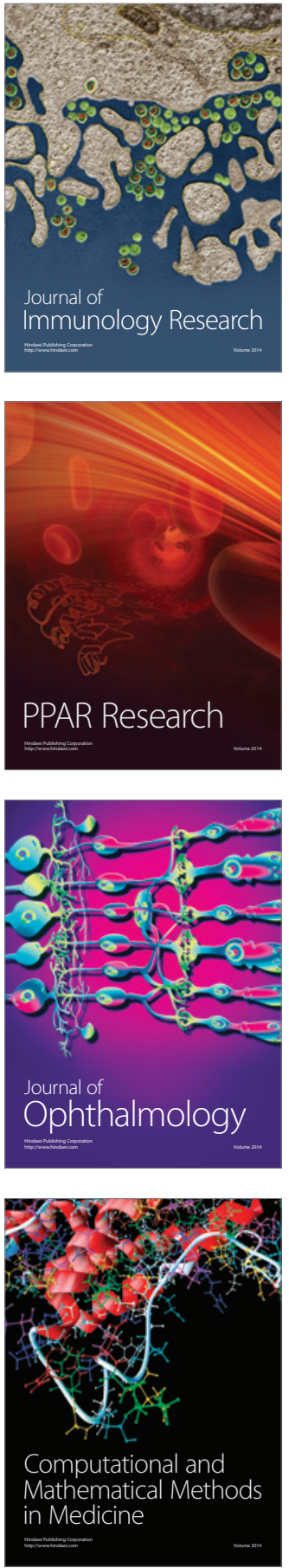

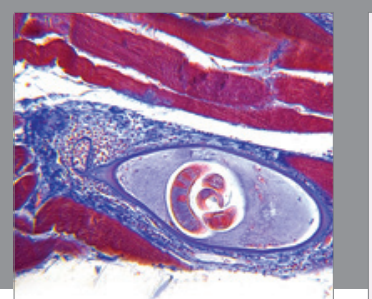

Gastroenterology Research and Practice

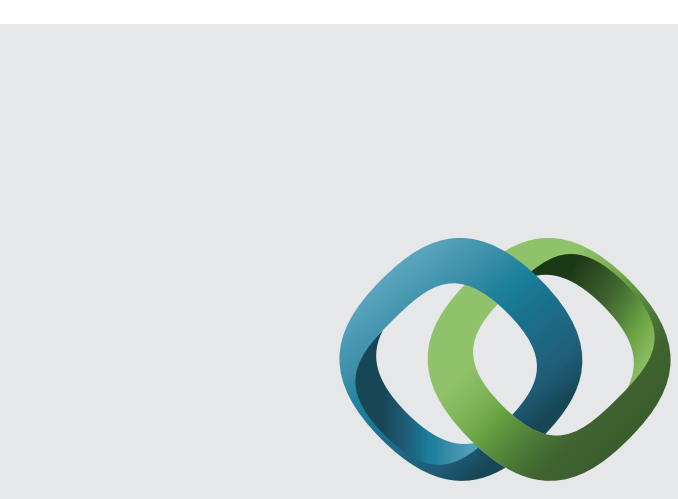

\section{Hindawi}

Submit your manuscripts at

http://www.hindawi.com
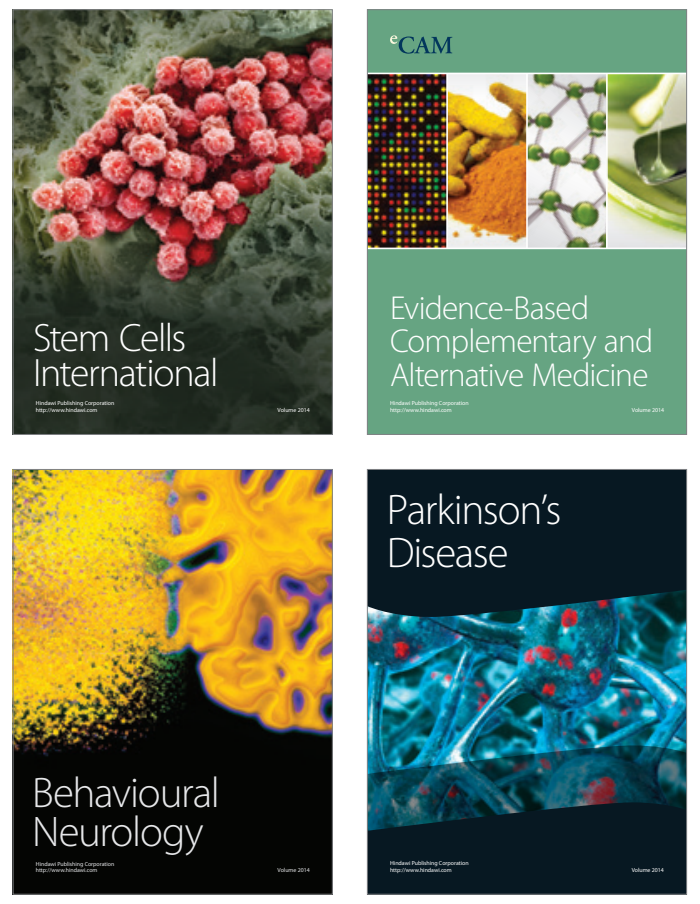
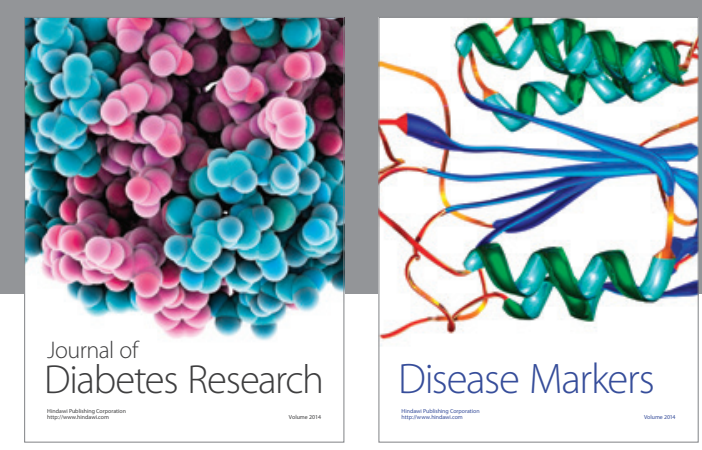

Disease Markers
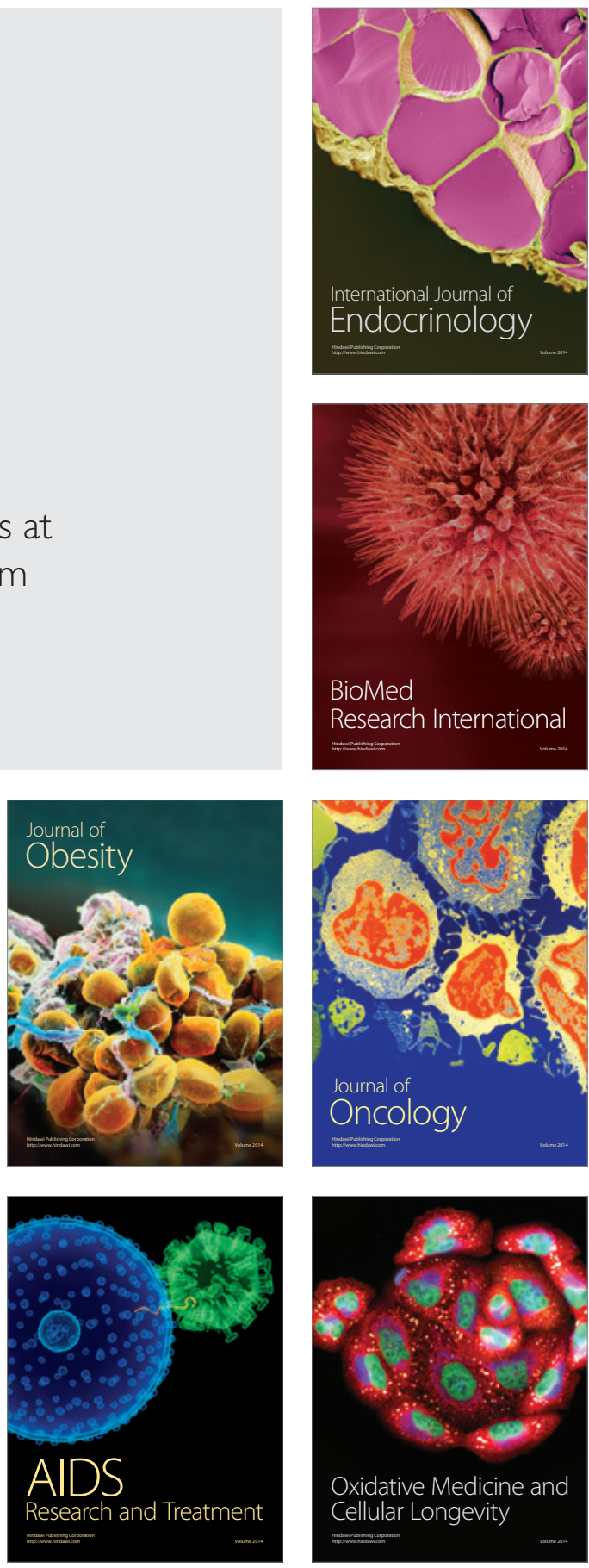